\title{
Sea Ice Observations in Polar Regions: Evolution of Technologies in Remote Sensing
}

\author{
Praveen Rao Teleti, Alvarinho J. Luis \\ Earth System Sciences Organization, National Centre for Antarctic and Ocean Research, Ministry of Earth Sciences, Goa, India \\ Email: alvluis1@gmail.com
}

Received June 27, 2013; revised July 31, 2013; accepted August 23, 2013

Copyright (C) 2013 Praveen Rao Teleti, Alvarinho J. Luis. This is an open access article distributed under the Creative Commons Attribution License, which permits unrestricted use, distribution, and reproduction in any medium, provided the original work is properly cited.

\begin{abstract}
Evolution of remote sensing sensors technologies is presented, with emphasis on its suitability in observing the polar regions. The extent of influence of polar regions on the global climate and vice versa is the spearhead of climate change research. The extensive cover of sea ice has major impacts on the atmosphere, oceans, and terrestrial and marine ecosystems of the polar regions in particular and teleconnection on other processes elsewhere. Sea ice covers vast areas of the polar oceans, ranging from $\sim 18 \times 10^{6} \mathrm{~km}^{2}$ to $\sim 23 \times 10^{6} \mathrm{~km}^{2}$, combined for the Northern and Southern Hemispheres. However, both polar regions are witnessing contrasting rather contradicting effects of climate change. The Arctic sea ice extent is declining at a rate of $0.53 \times 10^{6} \mathrm{~km}^{2} \cdot$ decade $^{-1}$, whereas Antarctica exhibits a positive trend at the rate of $0.167 \times 10^{6} \mathrm{~km}^{2} \cdot$ decade $^{-1}$. This work reviews literature published in the field of sea ice remote sensing, to evaluate and access success and failures of different sensors to observe physical features of sea ice. The chronological development series of different sensors on different satellite systems, sensor specifications and datasets are examined and how they have evolved to meet the growing needs of users is outlined. Different remote sensing technology and observational methods and their suitability to observe specific sea ice property are also discussed. A pattern has emerged, which shows that microwave sensors are inherently superior to visible and infrared in monitoring seasonal and annual changes in sea ice. Degree of successes achieved through remote sensing techniques by various investigators has been compared. Some technologies appear to work better under certain conditions than others, and it is now well accepted that there is no algorithm that is ideal globally. Contribution of Indian remote sensing satellites is also reviewed in the context of polar research. This review suggests different primary datasets for further research on sea ice features (sea ice extent, ice type, sea ice thickness, etc.). This work also examines past achievements and how far these capabilities have evolved and tap into current state of art/direction of sensor technologies. Effective monitoring and syntheses of past few decades of research pinpoint useful datasets for sea ice monitoring, thereby avoiding wastage of resources to find practical datasets to monitor these physically inaccessible regions.
\end{abstract}

Keywords: Sea Ice; Satellite Remote Sensing; Polar Regions; Albedo

\section{Introduction}

Earth comprises of approximately $71 \%$ of water which is stored in oceans and glaciers. Global and local weather is influenced by ocean-atmosphere-land processes. Polar regions (Arctic and Antarctic) exert much higher influence on global climate and heat budget due to high albedo that provides a positive feedback on atmosphere. Arctic sea-ice extends to $15 \times 10^{6} \mathrm{~km}^{2}$ at the end of winter $\left(7 \times 10^{6} \mathrm{~km}^{2}\right.$ in summer $)$ whereas Antarctic sea-ice occupies an area close to $18 \times 10^{6} \mathrm{~km}^{2}$, but by the end of melt season only $3 \times 10^{6} \mathrm{~km}^{2}$ area remains. So the polar regions are covered by sea ice to an extent of $20 \times 10^{6}$ $\mathrm{km}^{2}$ at any time. Figure 1 illustrates the average extend of sea-ice cover in Northern and Southern Hemispheres over a 25-year period (1979-2003) derived from National Snow and Ice Data Center (NSIDC) using satellite sensors.

The present trend determined from satellite observations reveals an asymmetrical effect of climate change on sea ice in the polar regions (Figure 2). Sea ice extent in Arctic has shrunken dramatically since the satellite observations started in 1970's. Arctic's maximum sea ice extent was more than $16.5 \times 10^{6} \mathrm{~km}^{2}$ in 1980 but it reduced to $15 \times 10^{6} \mathrm{~km}^{2}$ in 2011 , effectively showing $0.5 \times$ $10^{6} \mathrm{~km}^{2} \cdot$ decade $^{-1}$ loss of sea ice. On the other hand, Antarctic sea ice extent has experienced a slight increase 


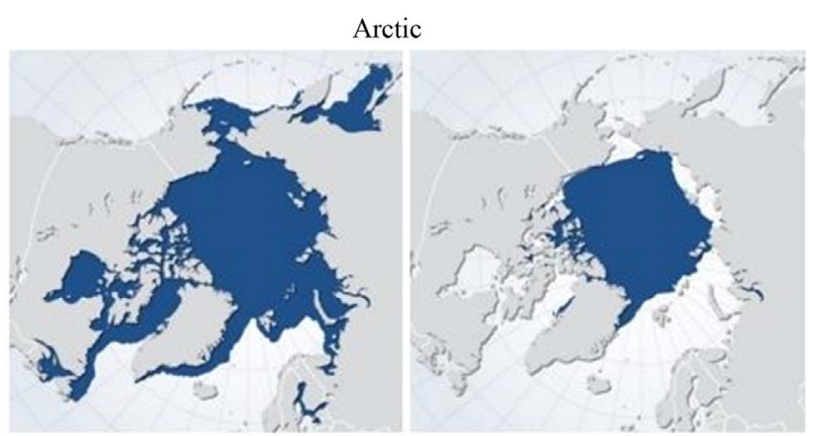

Antarctic

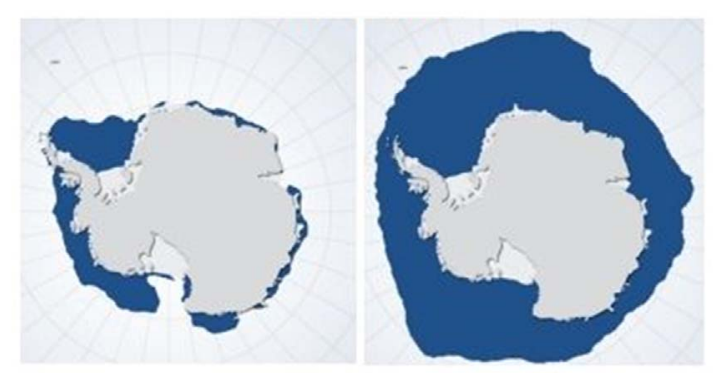

Figure 1. Average sea ice extent (blue color) in the polar regions, for the month of March (left) and September (right) (Images courtesy: Hugo Ahlenius, UNEP/GRID-Arendal).
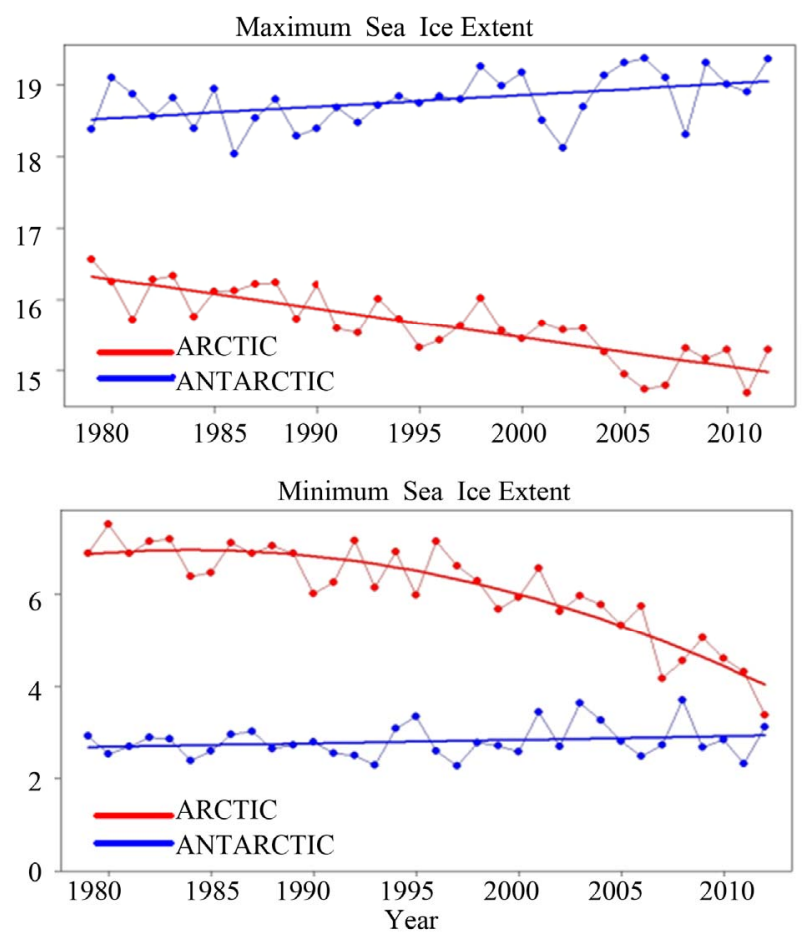

Figure 2. Maximum and minimum sea ice extent observed for Arctic and Antarctic, in million $\mathbf{k m}^{2}$ (Data courtesy NSIDC).

during same period, from less than $18.5 \times 10^{6} \mathrm{~km}^{2}$ in 1980 to more than $19 \times 10^{6} \mathrm{~km}^{2}$ in 2011 . The minimum sea ice extent at the end of austral summer in Arctic has undergone a dramatic change from over $6.5 \times 10^{6} \mathrm{~km}^{2}$ in 1980 to close to $3 \times 10^{6} \mathrm{~km}^{2}$ in 2012 . However, Antarctic minimum sea ice extent at the end of melt season shows a slight positive trend.

Figure 3 shows sea ice extent anomaly observed in Arctic and Antarctic, from 1980 to 2012. Arctic sea ice anomaly shows downward trend, and a sharp drop in the post-1997 period. Close to $2 \times 10^{6} \mathrm{~km}^{2} \cdot \mathrm{decade}^{-1}$ of sea ice cover has been lost permanently owing to climatic changes, including warming effects induced by anthropogenic greenhouse gases. On the other hand, Antarctic sea ice anomaly shows opposite trend, wherein approximately $0.5 \times 10^{6} \mathrm{~km}^{2}$ of sea ice area has been added since 1980. There has been statistically significant increases in surface air temperature (SAT), decrease in sea ice and warming of permafrost over large areas of the Arctic. On the other hand, most of the increase in Antarctic temperatures over the last 50 years is on the Antarctic Peninsula [1]. Weather systems in polar regions are far more complex than can be explained by any one of the external forcing such as increase in green-house gases or natural internal variability such as fluctuations in oceanic temperatures.

Climate in Arctic is essentially influenced by Arctic Oscillations (AO) and North Atlantic Oscillations (NAO). AO operates in two phases: in negative phase cooler air from Arctic penetrates mid-latitudes and reduces mean temperatures of that area, whereas in positive phase it helps the middle-latitude jet stream to blow strongly and consistently from west to east, thus keeping cold Arctic air locked in the polar region. AO can shift through phases quite frequently, year-to-year and even month-tomonth variability has been observed. AO has a strong correlation with NAO as both explain same underlying phenomenon. NAO also exhibits negative and positive phases. Positive phase occurs when Icelandic lows and Azores highs are strong, resulting in stronger pressure gradient across North Atlantic resulting in warm air penetrating the Arctic. During negative phase Icelandic

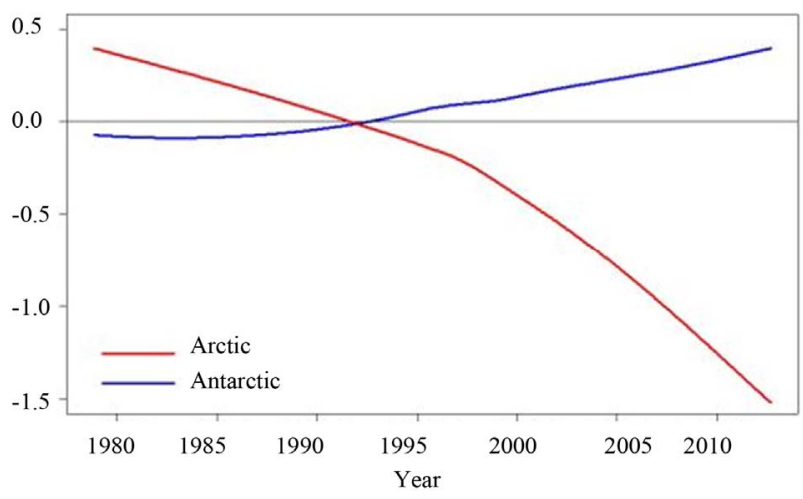

Figure 3. Sea ice extent anomaly observed in Arctic and Antarctic, in million $\mathbf{k m}^{2}$ (Data courtesy NSIDC). 
lows and Azores highs are weak, resulting in weakerpressure gradient, whereby colder polar air is pushed towards mid-latitudes. Due to natural swings in AO and NAO processes, it's difficult to assess impact of loss of sea ice on climate variations in Arctic regions, due to lack of observations. During 2010-2011, AO was strongly negative resulting in heavy snow blizzard on east coast of North America. Then in the following year, it switched to positive to weakly-negative phase and the same area experienced mildest winter in recorded history. What causes AO to switch signs frequently is not well understood.

Antarctic climate mainly depends on combined effects of Southern Annular Mode (SAM) and Antarctic Circumpolar Current (ACC). SAM usually defined as the normalised sea-level pressure gradient between $40^{\circ} \mathrm{S}$ and $65^{\circ} \mathrm{S}$. SAM operates in a nearly annular pattern with a large low pressure anomaly centered on the South Pole and a ring of high pressure anomalies at mid-latitudes. This leads to an important regional wind anomaly in a broad band around $55^{\circ} \mathrm{S}$, and the strength of westerlies that blow around the continent depends on phase and strength of SAM. Over the last 50 years, the SAM has shifted more into its positive phase with decreases of surface pressure over the Antarctic and corresponding increase at mid-latitudes. Enhanced westerlies have impact on ACC's mixing and upwelling resulting in unprecedented warming of the Southern Ocean (SO), consequently reducing its efficiency of $\mathrm{CO}_{2}$ sink. Stronger westerlies provide a thermal insulation cover around Antarctic, whereby the path of warm winds from midlatitudes which try to penetrate the high latitudes is blocked by extremely cool boundary of westerlies, resulting in storms like conditions. These storms carry moisture-laden warm air into the interior, contributing to heating of continental ice sheets. Full causes and effects of sea ice loss or gain on such processes are not fully understood.

Sea ice is known to play a part in the key processes of the polar climate system through $80 \%-98 \%$ reflection of incident energy. The high latitude climate is essentially the consequence of radiative heat loss and compensatory poleward oceanic and atmospheric heat transport [2]. Different interactions with atmosphere are responsible for varied climate conditions at the poles. Unlike Antarctic, which is a continent covered with ice sheet, the Arctic Ocean absorbs and retains much of its solar energy to release it slowly into ocean-atmosphere system. Sea ice provides an excellent insulation for heat exchanges between ocean-atmosphere, this insulation is particularly important in winter, when the sea-ice cover greatly restricts the loss of heat from the ocean to the very cold polar atmosphere. Sensible heat flux from the ocean to the atmosphere in the peak of Arctic winter (January) in the central Arctic basin has been reported to be $\sim 550$ $\mathrm{Wm}^{-2}$, when ocean and atmosphere are in direct contact with each other but is less than $50 \mathrm{Wm}^{-2}$ where the two are separated by sea ice of at least $80 \mathrm{~cm}$ thickness; this flux is negligible where sea ice layer is as thick as $3 \mathrm{~m}$ [3]. On the other hand, the latent heat flux in January is effective in transferring $\sim 145 \mathrm{Wm}^{-2}$ for an ice-free ocean, which is reduced to $<10 \mathrm{Wm}^{-2}$ for a sea-ice cover of 40 $\mathrm{cm}$ thick. Sea-ice cover works as a shield on ocean surface in winter when atmosphere is quite cold, which help oceans to maintain above zero temperature and support polar aquatic life.

Sea ice influences albedo or measure of reflectivity. In winter due to polar darkness, negative radiation balance results in extreme cooling of the polar regions. During summer, solar radiation is the only major heat source to warm the ocean-atmosphere-cryosphere system. The albedo for open sea water is in the range of $10 \%-15 \%$ whereas it is $80 \%$ for sea ice. If the sea ice is covered with fresh snow, the albedo can be as high as $98 \%$ which is six times more than that for the open sea water. Different values of albedo lead to an important factor in climatic system - the solar power absorption. Large ice cover drastically reduces solar energy absorption by ocean further reducing temperature, thereby stimulating ice growth. This leads to positive feedback mechanism, wherein it can reduce sea-ice cover when more solar energy is absorbed by the ocean, thereby increasing its temperature. Extent of sea ice has major influence on radiative flux balance [2].

Sea-ice not only impacts solar budget of earth but also maintains dynamic salinity equilibrium of the oceans. Temperature difference between equatorial and polar regions combined with global salinity differences operates oceanic current systems. As sea-ice forms, it rejects salt into surrounding ocean water and as sea-ice gets colder either due to gravitational pull or due to flushing out of the salt by melt ponds. This expelling of salt (brine) to the upper layer of the ocean can affect oceanic circulation; if the water density profile directly under the ice is weak enough then adding excessive salt leads to overturning circulation. Consequently, it leads to mixed-layer deepening, downwelling, and, in some instances, even bottom-water formation, the latter arising when the cold surface water downwells to the ocean bed. Dense cold water at the bottom moves along the ocean bed towards equator, warm water at equator moves towards polar regions to stabilize the temperature difference giving rise to major oceanic currents. These fluxes of heat and brine result in the most significant source of dense water for the world ocean [4]. This conveyor belt action keeps the ambient temperature moderate, for survival of life. Polar regions store vast amount of frozen fresh water in the form of sea ice, snow and glaciers, large scale melting 
can have a significant role in North Atlantic circulation [5], and this melt water contains considerable biological matter [6]. Even though sea ice plays a significant and complicated role, yet the end users (researchers, navigation operational personnel) are interested in small number of parameters.

Integrating the area of the pixels with $15 \%$ or more sea ice provides the total sea-ice area which is important to understand factors affecting seasonal variations in ice cover on year-to-year basis. Sea ice concentration is proportion of area covered by ice relative to open water in a pixel. A key prediction of the greenhouse-gas-induced climate change is that the sea ice extent will respond early to the altered conditions [7]. Sea ice thickness is very important parameter which is yet to be measured on a large scale with a reasonable accuracy. Till now researchers have fairly good idea in two-dimensions of sea ice, which gives only a partial picture. When estimates for sea ice extent are combined with thickness data, it is useful to understand mass/volume, heat, salt fluxes which is essential for global climate change study. Different types of sea ice are defined according to their development stage. New ice is the one that is formed recently which includes frazil ice, grease ice, slush and shuga. Next stage is nilas which forms a thin elastic crust of ice which easily bends on waves and swell. First Year Ice (FYI) is not more than one winter old, developing from young ice, generally greater than $30 \mathrm{~cm}$ thick. Then subsequently multi-year ice (MYI) which has survived at least one melt season is usually thicker in Arctic than Antarctic. Surface irregularities and micro-structures on the surface of ice are important as direct ice thickness measurements are considerably more difficult to accomplish than surface measurements using remote sensing. Techniques are being developed for estimating thickness from surface characteristics.

Sea ice is generally covered with snow, which can vary in thickness from a few centimeters to more than a meter. Snow cover acts as a thermal insulator influencing the heat exchange between the ocean and atmosphere through sea ice-snow interface, and it impacts sea-ice growth rates and overall thickness - a key indicator of climate change in polar regions. Snow depth is required to estimate sea-ice thickness using freeboard measurements made with satellite altimeters [8]. The snow cover also acts as a mechanical load that creates negative ice freeboard, pushing ice below the sea level. Resulting flooding can change the microwave signature of sea ice, introducing ambiguity and loss of back scatter signal. Sea ice in polar regions is constantly in motion either due to underlying ocean currents, glacial melt and runoff, or high speed katabatic winds in Antarctica. Drift velocity is important for glacial studies as well as in climatic analysis as it conveys rate of mass offloading into oceans by glaciers, which contributes to rise in global sea level. Traditionally, sea-ice drift observations were made aboard research vessels. This process was slow and biased towards accessible areas of sea ice.

Vast amount of sea ice acts as a natural probe placed into environment, which gives proxy indications of overall state of health of our planet. Polar regions are barometer where one can observe more accurately effects of changing climate due to polar magnification as a result of feedback mechanisms. Data from remote-sensing satellites are being used extensively in research to generate operational charts [9-13]. Satellites have been operational for over 40 years, providing observations on high spatial resolution which are essential to witness the effects of climate change. Satellite data are now primary source of initial data to drive coupled ocean-ice-atmospheric models and also provide independent data to validate the latter.

\section{Historical Sea-Ice Observations}

In the pre-satellite era, sea-ice observations were made by observer from the shore, ship, and aircraft. Whaling cruises recorded sea-ice data over a long period. Crew on each ship maintained logs of geographic positional information, together with observations of wind speed and direction. These logged positions can be considered as outlining sea-ice extent as ships followed their target along the ice edge. Antarctic whaling ship records show approximate sea-ice boundary for more than 100 years [14]. Since 1931, a record has been maintained for every whale caught including positional information and seaice type.

The International Whaling Commission maintains a database of 1.5 million records of each whaling expedition. The whaling season usually starts from October till April in the following year, which gives a circumpolar coverage of ice edge. The data is continuous since 1931 when recording began since 1987, with a gap during World War-II (1940-46). This data set provides nearaccurate ice boundary at different months around Antarctica. After reliable satellite observations were available, it was found that whaling records show close correlation with satellite data [15]. From 1950 onwards, upward looking sonar (ULS) has been used to chart sea-ice thickness along the track in the Arctic. The time is measured between outgoing and incoming sound signal which gives distance travelled by signal; pressure is measured continuously to estimate depth of sub-marine. Difference between the depth of submarine and distance travelled by sound wave provides the sea ice thickness [16-18].

The research vessels (USCGC Polar Star, Aurora Australis, Polarstern, etc.) were used to carry out visual observations on sea ice type, concentration, thickness and surface topography. Detailed logs have been maintained on many voyages over the past two decades. Usually a 
trained observer stands on ship's bridge taking notes on ice conditions along the ship route with ship's positional information [19]. One of the drawbacks of ship-based observations on sea ice thickness and its other characteristics is a lack of a standardised system for making and recording the observations. Merging data from different voyages is difficult, thereby limiting its usability in comprehensive analysis. In-situ observations on ice surface which are done by drilling into sea ice to capture most of the features. Ice cores also give detailed information about structure, composition and paleoclimate, but this method is very slow, time-consuming, and limited to accessible areas due to expensive logistics. Because of uncertainty in weather conditions and high logistic costs, the satellite remote sensing is only convenient method for studying polar regions.

\section{Satellite Observations}

\subsection{Early Satellite Systems}

For the vast and inaccessible polar regions, there was always a demand for means to observe large sea-ice surface with some continuity. The dawn of satellite era began in 1957 with launch of USSR satellite Sputnik. After its launch, there was race among nations to build satellites with better spatial and temporal resolutions and fly them in orbit as soon as possible.

\subsubsection{VIS and IR Sensors}

The first remote sensing satellite TIROS-1 was launched in April 1960 ushering development of improved remote sensing sensors. It carried a special television camera capturing global cloud cover. The early TIROS satellites orbited at a relatively low inclination hence, sea-ice observations were limited to regions between $60^{\circ} \mathrm{N}$ and $60^{\circ} \mathrm{S}$. Successive satellite sensors improved the spatiotemporal resolution of sea-ice extent observations, enabling studies on dynamics of sea-ice motion using advanced imaging instruments such as high-resolution visible \& IR cameras. Examples are the NOAA's Advanced Very-High Resolution Radiometer (AVHRR) which has resolution about $1-4 \mathrm{~km}$, a swath of about $2000 \mathrm{~km}$ and NASA's Moderate Resolution Imaging Spectrometer (MODIS) which has resolution about $0.25-1.0 \mathrm{~km}$ and a swath of about $2300 \mathrm{~km}$. Unfortunately from a sea ice perspective, over cast sky and polar nights make it difficult to use deploy these sensors in these conditions [20, 21]. Ref. [21] has used MODIS data to validate the satellite-derived temperature and inferred that they agree well with root mean square error of $1.7 \mathrm{~K}$ in clear-sky conditions. The longest earth remote sensing satellite series to serve the purpose is LandSat series (originally named Earth Resource Technology Satellite-1). For the first time LandSat-1 was launched in 1972 with a number of sensors: a three-camera return-beam vidicon (RBV) to obtain visible light and near-infrared photographic images of Earth, and four-channel multispectral scanner (MSS) to obtain radiometric images. Subsequently, LandSat-5 was launched which served the researchers for well over 28 years. It carried Thematic Mapper and Multispectral Scanner. Next in series was LandSat-7 which was launched in 1999 and carried a PAN camera with $15 \mathrm{~m}$ spatial resolution. A typical image of sea ice from LandSat 7 PAN is depicted on Figure 4.

\subsubsection{Passive Microwave Sensors}

Passive Microwave Sensors (PMS) were developed to make observations in all-weather conditions, by sensing the Earth's surface at centimeter-scale. The first remote sensing satellite was launched by Russia, which carried PMW sensors-Cosmos 243 in 1968 and Cosmos 384 in 1970. The polar orbiting Nimbus-5 carried an experimental Electrically Scanning Microwave Radiometer operating at $19.35 \mathrm{GHz}$. It measured brightness temperature from which cloud liquid water content, sea ice edge, and surface composition and soil moisture were derived.

After the ESMR period, a more advanced remote sensing instrument, the Scanning Multichannel Microwave Radiometer was operated aboard Nimbus-7 from 1978 to 1987 . It measured dual-polarised radiation at $6.63,10.69,18.0,21.0$, and $37.0 \mathrm{GHz}$. A similar instrument called Special Sensor Microwave Imager (SSM/I) on DMPS satellite carried a seven-channel four-frequency linearly polarized passive radiometer. It provided continuous measurements for more than 25 years and became an industry standard for passive radiometer design

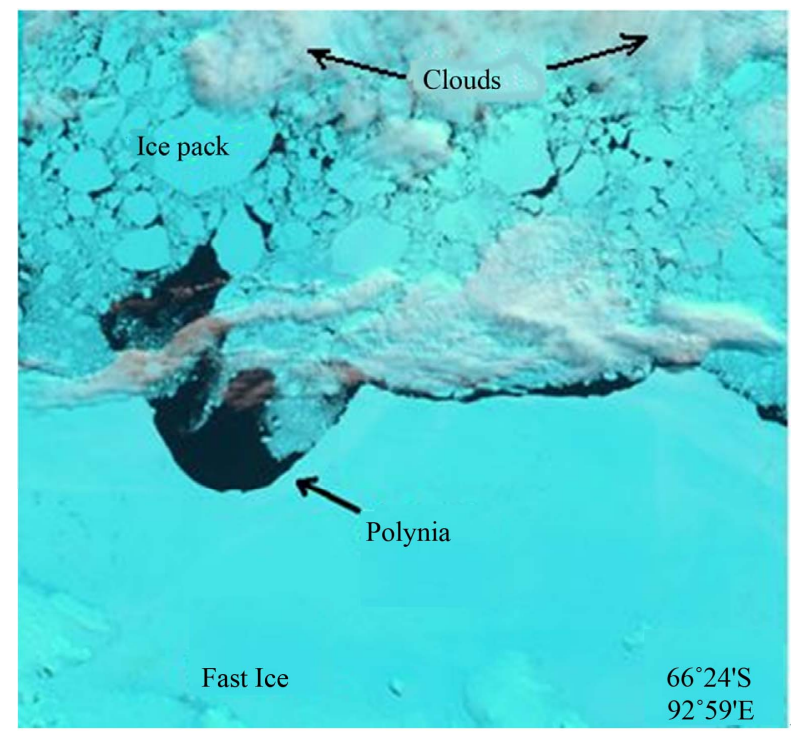

Figure 4. Landsat 7 PAN image showing land fast ice with ice pack near Mirny Station $\left(66.5^{\circ} \mathrm{S}, 93^{\circ} \mathrm{E}\right)$, East Antarctic. Clouds are also visible, length of diagonal of image is approx. 145 km (Image courtesy: USGS/NASA). 
$[11,22]$. The sea ice concentration using SMMR, SSM/I, and SSMIS is portrayed on Figure 5. The Successive Advanced Microwave Scanning Radiometer-Earth Observing System (AMSR-E) instrument aboard Aqua provided measurements of land, oceanic, and atmospheric parameters, including precipitation rate, sea surface temperature, and sea ice concentration. It provided passive microwave images in K-band $(0.75 \mathrm{~cm}$ to $2.5 \mathrm{~cm})$, $\mathrm{X}$-band $(\sim 2.5 \mathrm{~cm}$ to $\sim 4 \mathrm{~cm})$ with resolution of $4 \mathrm{~km}$. SSM/I, SMMR and PMW instruments were launched to record sea surface temperature and near-surface winds in all weather conditions for developing and testing global ocean circulation models.

\subsubsection{Active Microwave Sensors}

With demands for finer resolution of imagery, passive radiometer instruments proved inadequate. Typical passive microwave imagery had coarse resolution around 30 $\mathrm{km}$, which was suitable for overall trend observation rather than studying particular area or location. Even though later passive radiometer instruments like AMSR-E provided much higher resolution $(6 \mathrm{~km})$, it was inadequate. Active-microwave sensors transmit microwave signal and receives the backscatter that determines geophysical properties of the surface. These sensors include radar altimeters, scatterometers, side-looking real aperture radars (SLAR), and synthetic aperture radars (SAR). In 1970s and 1980s SAR was used for aircraft surveillance and for sea ice monitoring, in order to provide detailed maps of the sea ice conditions, especially in sectors of busy maritime traffic.

Space-borne SAR combines high spatial resolution with capability to illuminate the scene with preferred frequency and polarization, making it possible to observe sea ice with much better accuracy than visible and PMW methods. In 1978, Seasat was the first satellite that provided high-resolution SAR images of sea ice from June to October. After a long wait, the European Remote Sensing (ERS) program was launched in 1991. It represented a major milestone in satellite SAR remote sensing of sea ice, because the two satellites ERS-1 and ERS-2 have operated continuously for more than 10 years and recorded valuable data of ice-covered regions [24]. ERS-1 carried many innovative and advanced payloads to further earth observation and monitoring earth systems by using Radar Altimeter (RA), Scatterometer, and SAR operating in C-band. Its successor ERS-2 was launched in 1995 and worked till 2011.

Altimeter is a basically used for measuring the distance between satellite/aircraft and the ground below it. The Radar Altimeter (RA) is a Ku-band (13.8 GHz) nadir-pointing active microwave sensor designed to measure the time return echoes from ocean and ice surfaces. Operating in one of two operational modes (ocean or ice) the RA provides information on significant wave height, surface wind speed, sea surface elevation, which relates to ocean currents, geoid and tides. The RA data is suitable for studying thickness of sea ice and ice sheets but contains ambiguity from the fact that radar signal may be reflected from a undetermined point either from snow-air or snow-ice interface.

Scatterometers were developed to measure the reflection or back-scattering produced by ocean with specially designed microwave radars. When compared to altimeter which is nadir-pointing sensor that collects data along a narrow beam, the scatterometer collects data within a wide swath centered on the satellite track. Laser Altimeter (LA) sends light pulses and calculates echo time of each returning pulse. Ice, Cloud, and land Elevation Satellite (ICESat) dataset creates elevation maps of target surface, which can be used to detect topography of ice sheet and snow above the sea water. Since laser pulses are impenetrable into snow cover, they are preferred to measure height of sea ice with respect to ocean level.

\subsection{Indian Remote Sensing Satellites}

The Indian remote sensing program commenced with successful launch of Bhaskara-I on June 7th 1979 and subsequently an improved version-Bhaskara II was put in orbit on November 20th 1981. ISRO is principle agency for building, launching and maintaining satellites which serve national interests. India's first indigenously developed operational remote sensing satellite was IRS-1A which was launched in 1988. This launch marked the beginning of India's earth remote sensing system, bringing India at par with other developed nations.

IRS-1A and IRS-1B, the first two satellites in the series, generated natural resources information such as crop acreage, production estimate, drought monitoring and assessment, disaster mapping, urban planning, environmental impact analysis, etc. IRS-1A carried Linear Imaging Self Scanner (LISS)-I which operated in four spectral bands in the range of 0.48 to $0.86 \mu \mathrm{m}$. Each band uses 2 CCD's with 7-bit quantization and had swath width of $148 \mathrm{~km}$. LISS-II was similar to LISS-I but with higher spatial resolution and smaller swath. LISS-I had resolution of $72.5 \mathrm{~m}$ whereas LISS-II had $36.25 \mathrm{~m}$. After successful launch and operations of IRS-1A, improvements were carried out like time tagged command capability to enable multiple payload operations. The next series of remote sensing satellites were IRS-1C and IRS-1D. These satellites were built and operated using advanced techniques such as three-axis body stabilized spacecraft. IRS-1C carried three sensors: panchromatic (PAN), LISS-III and Wide Field Sensor (WiFS).

PAN camera operates in single spectral broad band: $0.50-0.75 \mu \mathrm{m}$ imaging ground segment of pixel $5.8 \mathrm{~m}$ 
and covered a ground swath between 63 and $70 \mathrm{~km}$ (at nadir). New improved LISS-III operates in four bands in the range of $0.52-1.70 \mu \mathrm{m}$, e.g., visible (B2: $0.52-0.59$ $\mu \mathrm{m}),(\mathrm{B} 3: 0.62-0.68 \mu \mathrm{m})$, near IR (B4: $0.77-0.86 \mu \mathrm{m})$ and short wave IR (B5: $1.55-1.70 \mu \mathrm{m})$. Spatial resolution and swath for visible and NIR is $23.5 \mathrm{~m}$ and $141 \mathrm{~km}$ respectively. For SWIR resolution and swath width is $70.5 \mathrm{~m}$ and $148 \mathrm{~km}$. Water and land resource management are primary application for this payload.

The WiFS was designed to collect data in $0.62-0.68$ $\mu \mathrm{m}$ and $0.77-0.86 \mu \mathrm{m}$. It has a wide ground swath of $728-812 \mathrm{~km}$ with resolution of $169-188.3 \mathrm{~m}$. With the launch of IRS-P4/Oceansat-1, India achieved a major milestone in remote sensing capabilities. The first payload-Ocean Colour Monitor (OCM) was designed primarily to monitor and document chlorophyll concentration, phytoplankton blooms, atmospheric aerosols and particulate matter. It had spatial resolution and ground swath width of $360 \mathrm{~m}$ (along track), $236 \mathrm{~m}$ (across track) and $1440 \mathrm{~km}$ respectively. The second payload-Multifrequency Scanning Microwave Radiometer (MSMR) aboard IRS-P4 measured microwave radiation in 6.6, $10.65,18,21 \mathrm{GHz}$ in both horizontal and vertical polarization. It measured sea surface temperature, wind speed, cloud water content, and water vapor content in the at-

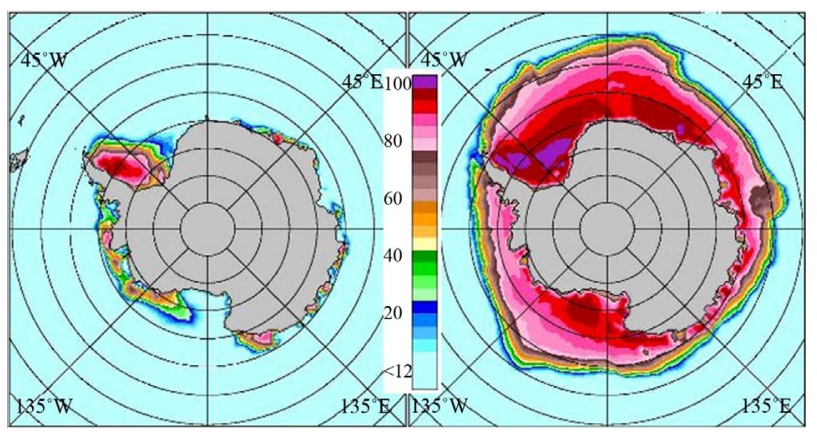

Figure 5. Average ice concentrations for February and September (1979-2010) as derived from SMMR, SSM/I, and SSMIS satellite observations (Image courtesy [23]).

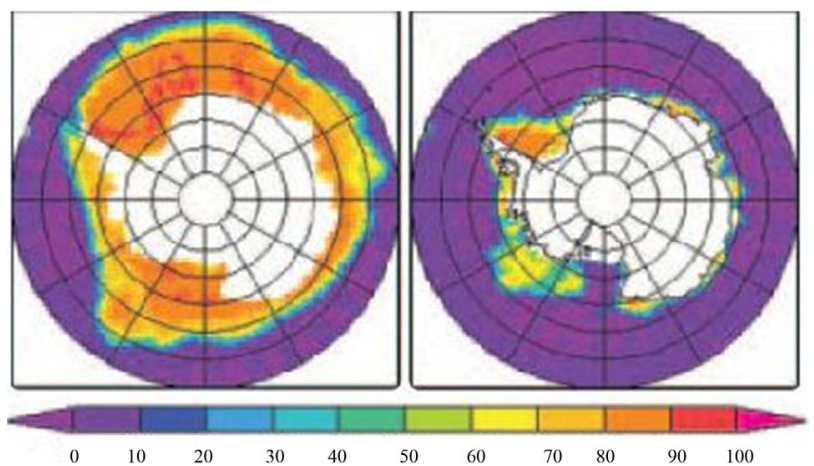

Figure 6. Monthly average sea-ice concentration (in \%) derived from MSMR, September 1999 (left) and January 2000 (right) (Images courtesy [25]). mosphere. It was also found suitable for distinguishing sea ice types through the use of microwave imaging rather than using visible images alone [25]. Figure 6 is an example of Antarctic sea ice concentration derived from MSMR using $18 \mathrm{GHz}$ channel in horizontal polarization to distinguish between ocean water and sea ice carried out by Indian researchers [25].

\section{Current State of Technologies}

Most earth remote sensing missions are deployed in polar sun-synchronous orbit, which offers an enormous advantage for remote sensing of polar regions. Whereas a given sensor might pass over a tropical location only once during daylight hours, at high latitudes, the space craft's orbits converge and the sensor's cross-track swaths begin to overlap at poles. Thus, it's often possible to view a high Arctic or Antarctic location several times in a day with the same sensor, which makes remote sensing a powerful tool. One of the primary objectives for polar research is to monitor sea ice variations in both Arctic and Antarctic. The sections below highlights preferred sensor datasets derived from different sensors (Table 1) for observing and studying typical sea ice features.

\subsection{Sea-Ice Extent and Concentration}

Since the inception of satellite data collection, visible sensors have been used to estimate sea ice cover and concentration. Visible sensors have the disadvantage of being quite weather sensitive-images are obscured by clouds, ice clouds, and fog-while SAR sensors, especially in the higher resolution modes, have a limited coverage/ swath. This is why the sensor of choice for determining sea ice extent is often a PMS. Satellite microwave data have succeeded in generating an exceptionally complete and reliable record of the ice extent for both polar regions over the past 35 years [26-28], and this record continues today.

Using brightness temperature from ESMR on-board Nimbus-5 [27] delineated ice boundary of Antarctic sea ice for the 1973-1976 period for the first time. The data is represented in color coded maps which show brightness temperature, ice extent and so on. Similar efforts were made to chart the brightness temperature of northern polar ocean elsewhere [28]. The Arctic and Antarctic sea ice was mapped for the first time in color coded scheme showing ice concentrations and ice extent (Figure 7). The ESMR data fuelled further inquiry into polar climate processes, paving way for more advanced highresolution sensors.

With rising global temperatures many research works suggested that Antarctic sea-ice cover would decrease [29], but predictions were at best speculative. One climate model predicted that with increasing temperatures, 
Table 1. Evolution of sensors specifications used for remote sensing in the past and present.

\begin{tabular}{|c|c|c|c|c|}
\hline Sensor Category (Year) & Sensor Name & Satellite Platform & Swath Width (km) & Resolution (m) \\
\hline \multirow[t]{9}{*}{ VIS/IR (1960) } & MSS & LandSat series & 185 & 80 \\
\hline & AVHRR 1-3 & NOAA 17 & 2900 & 1100 \\
\hline & AWiFS & IRS P7 & 740 & 56 \\
\hline & $\mathrm{CCD}$ & INSAT $3 \mathrm{~A}$ & Global Coverage & 1000 \\
\hline & ETM+ & LandSat 7 & 185 & 15 \\
\hline & GeoEye-1 MS & GeoEye & 15 & 1.56 \\
\hline & LISS I-IV & ResourceSat-1,2 & 70 & 5.8 \\
\hline & MODIS & Terra, Aqua & 2330 & 250 \\
\hline & OCM & OceanSat 1,2 & 1440 & 236 \\
\hline \multirow[t]{7}{*}{ Passive Microwave (1968) } & ESMR & Nimbus 5 & 1280 & 25,000 \\
\hline & SMMR & Nimbus 7 & 600 & 22,000 \\
\hline & MSMR & OceanSat 1 & 1360 & 22,000 \\
\hline & $\mathrm{SSM} / \mathrm{I}$ & DPMS & 1400 & 15,000 \\
\hline & AMSR-E & Aqua & 1445 & 4000 \\
\hline & MRW & EnviSat & 20 & 20,000 \\
\hline & MWR & Sentinel 3 & 20 & 20,000 \\
\hline \multicolumn{5}{|l|}{ Active Sensors (1978) } \\
\hline \multirow[t]{6}{*}{ SAR } & SAR & SeaSat & 100 & 25 \\
\hline & AMI SAR & ERS 1,2 & 100 & 10 \\
\hline & ASAR & EnviSat & 100 & 28 \\
\hline & RISAT SAR & RISAT 1 & 30 & 3 \\
\hline & SAR & Sentinel 1 & 50 & 8 \\
\hline & RadarSat SAR & RadarSat 1,2 & 20 & 3 \\
\hline Optical Sensors & GLAS & IceSat & NA & 70 \\
\hline \multirow[t]{5}{*}{ Radar Altimeter } & ALT & SeaSat & 2 & NA \\
\hline & RA & ERS 1,2 & NA & 16 \\
\hline & RA-2 & EnviSat & NA & NA \\
\hline & Siral & CryoSat 2 & NA & NA \\
\hline & SRAL & Sentinel 3 & NA & 300 \\
\hline \multirow[t]{3}{*}{ Scatterometer } & ASCAT & Metop A & 500 & 25,000 \\
\hline & SASS & Seasat & 500 & 50,000 \\
\hline & Scat & OceanSat 2 & 1400 & $2,500,000$ \\
\hline
\end{tabular}

sea ice cover in Antarctic would also decrease [30]. It has been deliberated on the validity of one model over other; only reliable and long-term data could put an end to speculation. Using data from the SMMR onboard the Nimbus-7 satellite from October 1978 to August 1987 and SSM/I data from July 1987 to December 1998, a positive trends in sea ice concentration and sea ice extent were found. Regionally, the trends in extent are positive in the Weddell Sea, Pacific Ocean, and Ross Sea sectors, slightly negative in the Indian Ocean, and negative in the 
Bellingshausen/Amundsen seas sector [31].

Using the data from MSMR on-board IRS P4/ OceanSat-1, large-scale Antarctic sea-ice features were deciphered by using the brightness temperatures to contrast ocean water from sea ice [32]. Researchers also developed polarization $\left\{\mathrm{PR}=\left[T_{b f}(\mathrm{~V})-T_{b f}(\mathrm{H})\right] /\left[T_{b f}(\mathrm{~V})-\right.\right.$ $\left.T_{b f}(\mathrm{H})\right]$, where $T_{\mathrm{b}}=$ brightness temperature, $f=10$ or 18 $\mathrm{GHz}\}$ and gradient algorithm $\left\{\mathrm{GR}=\left[T_{b 18}(\mathrm{P})-T_{b 10}(\mathrm{p})\right] /\right.$ $\left[T_{b 18}(\mathrm{p})-T_{b 10}(\mathrm{p})\right]$, where $\mathrm{p}$ is horizontal or vertical polarization $\}$ which improved detection of sea ice concentration by using MSMR and SSM/I data Figure 8 [25]. Others used data from OCM to decipher sea ice features in Antarctic [33]. OCM sensor was originally intended to detect color changes in the oceans (chlorophyll-a) but it has been found useful to study sea ice characteristics. With advanced sensors like AMSR-E sea ice extent have
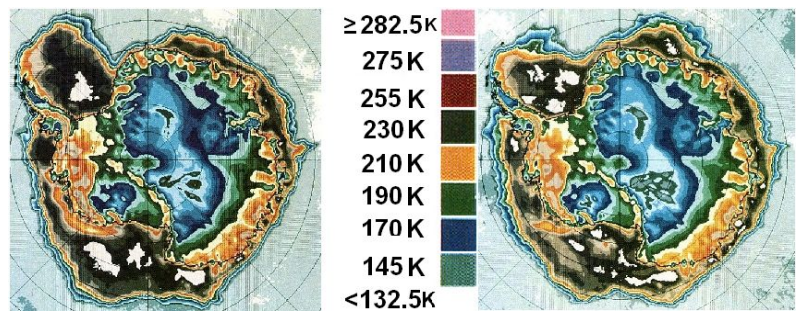

Figure 7. Mean monthly brightness temperature for May 1975 and 1976 (Image courtesy ref. [27]).

(a)

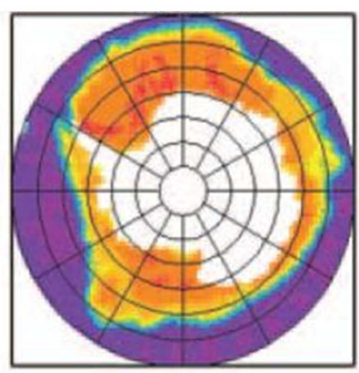

MSMR

(b)

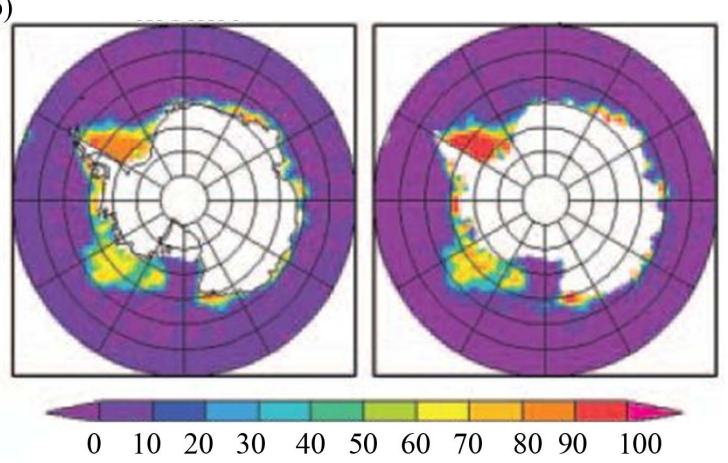

Figure 8. Comparison between monthly average sea-ice concentration images from MSMR polarization ratio/gradient ratio (PR/GR)-based algorithm and SSM/I for (a) September 1999 and (b) January 2000 (Image courtesy ref. [25]). been observed with unmatched spatial and temporal resolutions. Researchers undertook a comparative study using AMSR-E data and historical SSM/I data from 1987 to chart the sea ice extent [34]. They found that the data from AMSR-E showed 10\% - 15\% improvement over that of SSM/I because of better spatial resolution. Estimates of Antarctic and Arctic sea ice extent showed a close agreement with estimates obtained from MODIS data. Similarly, Arctic sea ice extent minimum was recorded in September 2011 using AMSR-E data, owing to its high resolution.

\subsection{Sea Ice Thickness}

Estimation of sea ice thickness on a large spatial scale is challenging yet number of efforts has been made using in-situ, model simulations and remote sensing. Ground missions and ice core drilling are always reliable and fool proof methods for measuring sea ice thickness. However, these have their set of limitations like unreasonable demand of time, effort and resources [35]. A number of ways has been suggested to estimate sea ice thickness from remote sensing data by using surface albedo, active SAR images, and PMW images. First, surface albedo methods are discussed below.

Researchers have used optical sensor data to estimate sea ice thickness [35,36]. Reference [35] proposed a direct approach to successfully estimate sea ice thickness over a large spatial area using MODIS data. It is based on a retrieval model of an exponential relationship between albedo and ice thickness. Albedo values were derived using algorithm developed elsewhere [37,38]. Others used a more comprehensive method to accurately estimate sea and lake ice thickness with optical (visible, near infrared, and infrared) satellite data [36]; the method correlates sea ice thickness to thermodynamic and radiative flux model, using data from NOAA's AVHRR and NASA's MODIS.

NOAA's AVHRR data have been used to estimate quantitatively the thickness of thin sea ice [39]. They combine a one-dimensional thermodynamic sea ice model with the satellite observations of surface temperature and albedo to estimate ice thickness for each pixel and then added all pixels in each scene to compute the thickness distribution of ice down to a meter. But extending the same principle, more thick sea ice can be approximated. The method was validated with in-situ upward looking sonar (ULS) measurements at specific points.

When satellite-based sea ice thickness estimates were compared with those from moored ULS, the error was found to be less than $2 \%$ for each $10-\mathrm{cm}$ thickness bin. It was found that larger divergence was most likely to arise at the thin end of the distribution (up to $20 \%$ near the ice 
edge), as a consequence of coarse spatial resolution of AVHRR which causes some leads, especially young narrow leads, to be viewed mixed with thicker ice [40]. Recently, high resolution PMS data has been used to derive sea ice thickness. Researchers employed Microwave Imaging Radiometer using Aperture Synthesis (MIRAS) operated in L-band $(1.4 \mathrm{GHz})$ onboard Soil Moisture and Ocean Salinity (SMOS) as secondary source to derive the thickness of thin sea ice. An innovative algorithm has been developed to retrieve sea ice thickness based on Level 1C brightness temperatures [41]. These results were compared with an ice growth model and independent sea ice thickness estimates from MODIS thermal infrared imagery Figure 9. The root mean square error between the SMOS and the MODIS (sea ice thickness) derived elsewhere was found to be 10 $\mathrm{cm}$ with a negative bias of $2 \mathrm{~cm}$ [40]. The pixel-by-pixel correlation was estimated to be 0.5 . Similarly, others used Terra MODIS data in combination with Envisat Advanced SAR (ASAR) Wide Swath Mode (WSM) images to estimate sea ice thickness [42].

Laser Altimetry (LA) can also estimate ice sheet thickness by calculating free boarding height using the Geoscience Laser Altimeter System (GLAS) onboard ICESat which is operated in near-infrared $(1064 \mathrm{~nm})$ wave-

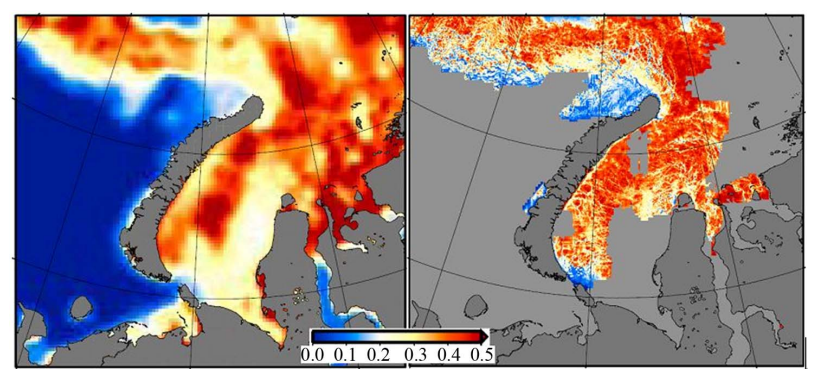

Figure 9. Sea ice thickness (m) map of the Kara Sea derived from (left) SMOS and (right) MODIS, on Dec. 26, 2010 [41].

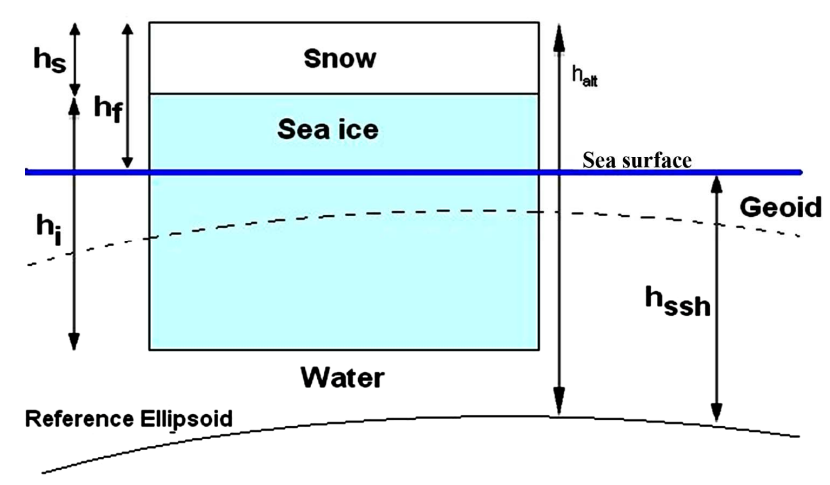

Figure 10. Simple schematic representation of snow covered sea ice in open sea water. Total sea ice thickness (hi), snow thickness (hs), freeboard (hf), sea surface height above the reference ellipsoid (halt), and sea surface height (hssh) are shown. length. In LA the time taken by laser pulse to return from ground is measured very accurately to calculate distance between spacecraft and earth surface below. The returning pulse is recorded by a 1 meter diameter telescope and spots produced on the Earth's surface represent a circular region with $70 \mathrm{~m}$ diameter. Using ICESat data, the sea ice thickness above sea water can be retrieved after subtracting the reference height from the sea surface. The height of sea ice above sea water consists of snow and ice. General buoyancy equation is used to estimate the total sea ice thickness. Densities of sea water, snow and ice are inferred from past in-situ experiments. The thickness of snow above sea ice is recovered from high resolution PMS, such as AMSR-E. It is assumed that sea ice is in hydrostatic equilibrium. Figure $\mathbf{1 0}$ illustrates the means of computing sea ice thickness using LA. This mechanism has been used to estimate sea ice thickness in Antarctic sea ice [43]. Approximate thickness of sea ice can be expressed by estimating ice type and their corresponding average thickness. This method is quite crude but can be used to generate maps very quickly using readily available PMW data.

\subsection{Sea Ice Type}

Microwave emission comes from different layers such as the snow surface, snow-ice interface and the internal ice layers, and depends on the frequency. Open water is reflective in the microwave band and emits little energy, and has strong polarization. In contrast, first-year ice is highly emissive and has weak polarization, while the multiyear ice emission falls between that of water and the first-year ice. Consequently, the brightness temperature recorded by the sensor depends on the type of surface from which the radiation originates.

PMS is effective in differentiating different ice types. Substantial spectral and polarimetric differences in emissivity exist between FYI, MYI, and the open ocean, and a variety of algorithms have exploited these properties to map the spatial and temporal extent of these surface types. Reference [44] reported that the optimum and round-the-year threshold for distinguishing the sea-ice from open water in the Antarctica using the MSMR 18 $\mathrm{GHz}$ (horizontal polarization) on board OCEANSAT-1 is $\mathrm{T}_{\mathrm{B}}>130 \mathrm{~K}$. Reference [45] developed a new algorithm called Environment Canada's Ice Concentration Extractor (ECICE), to calculate total ice concentration and partial concentration of each ice type using remote-sensing observations. They used the $85 \mathrm{GHz}$ and $37 \mathrm{GHz} \mathrm{SSM} / \mathrm{I}$ channels and AMSR-E to compare algorithm performance relative to ice type charts prepared by Canadian Ice Service (CIS). They also explored the suitability of 85 $\mathrm{GHz}$ SSM/I channel instead of using high resolution AMSR-E data. Performance has been mixed, the algo- 
rithm successfully identified ice types when concentration was nearly $100 \%$, but as total ice concentration decreased estimates from ECICE using 85-GHz observations deviated more from CIS estimates than the corresponding deviation when $37-\mathrm{GHz}$ data were used.

Reference [46] suggested using fusion of SAR data with PMS data to remove ambiguity in identifying different ice types. Microwave emissivity is dependent on dielectric constant of sea ice which can change due to number of reasons such as desalination, as ice gets old or due to melting, negative free-boarding due to snow cover which can change passive microwave signatures randomly. Similarly, [47] considered suitability of combining AVHRR images and ERS-2 SAR images to study different ice types in Antarctica. Others studied viability of SAR images from ENVISAT (C-band HH polarization) using Neural Network (NN) based algorithm and Bayesian algorithm to discriminated different sea ice types [48]. The sea ice types selected for classification were MYI, deformed FYI, level first-year, and open water/nilas. The $\mathrm{NN}$ was used to run classification algorithm on the training data. The classification results of these images were also compared with ice charts issued by Arctic and Antarctic Research Institute (AARI), where MYI and FYI have been discriminated. The total classification accuracies determined by the confusion matrix between classification results and ice charts were found to be $79.3 \%$ for MYI and $92.5 \%$ for FYI.

\subsection{Surface Roughness}

Various remote sensing techniques can be used to identify and observe surface texture and roughness. One such technique is SAR images which measures different backscatter coefficients arising from surface irregularities. Images from ESAR, EMISAR, RADARSAT, ERS- and -2 sensors were used to establish relationship between radar signatures and ice deformation, surface roughness and ice thickness [48]. Various images with different frequencies and polarization were studied for optimal detection of surface features (for example, Barents sea ice image shown in Figure 11). They highlighted advantages and disadvantages of using C-band, L-band with varying polarizations, incidence angles, and spatial resolution to detect sea ice roughness.

Using data from the Multiangle Imaging Spectroradiometer (MISR) on board NASA's Terra satellite [50] exploited multi-angular emissivity of target surface to detect surface features and roughness. MISR captures microwave radiances simultaneously with different radiometers placed at different angles. This technique uses angular signatures of ice sheet and sea ice surfaces, similar to spectral signatures that are used in multispectral classification. It was found that MISR image showed

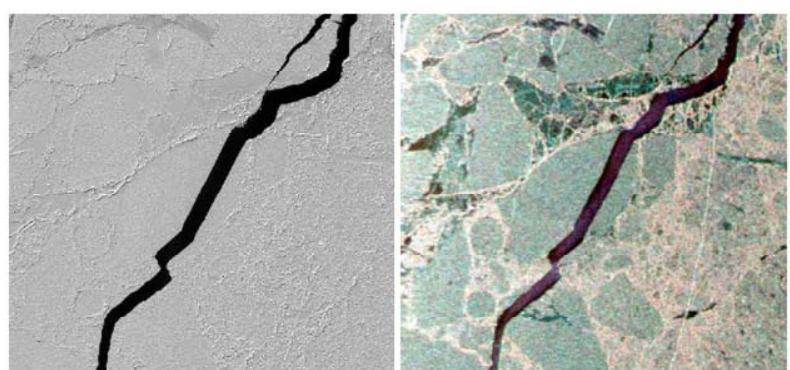

Figure 11. Barents Sea ice image: Optical (left) and ESAR (right). SAR image: L-Band R-HV, G-HH, B-VV polarizations. Deformed and rough ice is bright patches, thin ice as dark green patches, and open water as dark features (Images courtesy ref. [49]).

a good agreement with sea ice types that are observed in SAR imagery and ice charts derived from the National Ice Centre (NIC). It may not be superior to SAR imagery but in cases where melt season starts and SAR data are not useful, multi-angular optical data could provide secondary ice-mapping information. Others used AMSR-E channels $6.9,10.7$, and $89 \mathrm{GHz}$ to estimate small-scale surface roughness over the Arctic oceans in order to retrieve the total and MYI concentrations by using ARTIST sea ice (ASI) and polarization corrected temperature (PCT) algorithms, respectively [51]. The results are promising owing to high spatial resolution. On the other hand, [52] developed a method that uses LA data from GLAS/ICESat and demonstrated that very minute changes $(\sim 2 \mathrm{~cm})$ in the sea ice texture can be tracked by mapping the sea ice surface roughness derived from laser pulse returning from target surface.

\subsection{Snow Cover}

Large-scale snow cover observations are very limited in the Arctic and Antarctic polar regions. A number of researchers [53-56] used SMMR passive microwave data to extract snow parameters. They used distinct brightness temperatures of snow cover to estimate monthly and annual snow cover area. Since then, many different algorithms to map snow cover and snow water equivalent (SWE) using PMS data have been developed and tested [57-59]. Reference [57] developed a wet snow algorithm using $37 \mathrm{GHz}$ dual-polarization channel of SSM/I for the open prairie region of western Canada. The algorithm was used to identify areas of wet snow and discriminate them from areas of snow-free land. Others estimated the snow accumulation from satellite LA [60]. They used PMS data to identify the extent and timing of new snow on the Antarctic ice sheets, and used cross-over elevation measurements from GLAS/ICESat to estimate the amount of new snow over the ice sheets. The total snow depth over sea ice, however, cannot be discerned using this technique. 
Reference [61] derived snow depth at $25 \mathrm{~km}$ spatial resolution from SMMR data on board NIMBUS-7. Data for the period 1978 to 1987 were used to compare the average monthly snow-cover area derived from the NOAA/NESDIS and USAFGWC analyses to SMMR data. The snow cover derived from SMMR is in good agreement with NOAA/NESDIS and USAFGWC analyses, but showed significant deviation in the month of June, which is the snow annual melt season. Others developed an algorithm to calculate snow depths from PMS radiance [62]. However, there exists no algorithm to derive snow depth with reasonable accuracy better than 5 $\mathrm{cm}$ [63]. Reference [64] used radiances from AMSR-E data to derive snow depth among other parameters in the Arctic and the Antarctic. Similarly, other researchers [65] developed an algorithm to derive snow depth from high resolution AMSR-E data. The model required snow grain size and density of snow pack, as prior information. It has been shown dynamic algorithm works better then static ones.

Reference [66] pointed out that LA could measure the elevation of the air-snow interface due to the high optical reflectivity of the snow surface, while the radar altimeter could measure the elevation of the snow-ice interface under cold and dry conditions. Using LA such as GLAS/ICESat, total (sea ice + snow) height could be determined as light reflects from snow surface while using satellite radar altimeters, such as Cryosat-2 and Envisat, snow depth could be retrieved as radar penetrates snow and returns the scattered signal from sea ice surface. Detection of snow melting is very vital for climate studies and effective water management. Using NASA's scatterometer (NSCAT) data [67] identified snow pack ripening, however, melt and freeze events, could not be retrieve from the data to provide crucial details about regional climate. These satellite observations validated with in situ measurements from the Greenland Climate Network stations. On the other hand, [68] developed a blended snow product to map global snow cover extent utilizing MODIS, AMSR-E PMS data and QuikSCAT scatterometer data.

\subsection{Sea Ice Velocity/Drift}

Various remote sensing technologies and methods have been suggested to track sea ice motion and drift. Reference [69] used individual channels of $37 \mathrm{GHz}$ and 85 $\mathrm{GHz}$ of SSM/I to estimate motion of sea ice. They reported that the difference between buoy observations and satellite estimate tend to increase if large local velocity gradients exist. Standard deviations ranged between 5 and $12 \mathrm{~km}$, or about $4.2 \mathrm{~cm} \cdot \mathrm{s}^{-1}$ using 3-day displacements in the Arctic Basin, $6.1 \mathrm{~cm} \cdot \mathrm{s}^{-1}$ using 1-day displacements in Fram Strait, and $6.9 \mathrm{~cm} \cdot \mathrm{s}^{-1}$ in the Weddell Sea. Other researcher used wavelet approach to retrieve sea ice velocities from NSCAT data as well as SSM/I, and the results suggest that this approach has better ability to track motion for in Arctic and Antarctic regions [70].

Reference [70] used a single wavelet scale which gives fewer number of motion vectors, while [71] used multiple wavelet scales producing a larger number of vectors. Various methods for tracking and gridding low-resolution radar and radiometer ice motion using ERS-1/2, NSCAT Scatterometer and SSM/I data have been devised [72]. Weddell Sea buoys and satellite derived motion vectors showed significant divergence. In Antarctic, ice drift retrieval is more difficult due to faster ice-drift, more variable ice conditions, and more moisture in the atmosphere. Global coverage can only be mapped from satellite data, giving ice displacement vectors with moderate spatial and temporal resolution. Figure 12 was constructed using SSM/I brightness maps. Further analysis and comparison have been done on various methods to measure sea ice drift by [73].

Reference [74] compared satellite-derived sea-ice motion dataset obtained from the US NSIDC with daily ice drift from drifting buoys between 1989 and 2005. The satellite data were derived from daily composites of PMS measurements by means of a cross correlation method and were supplemented with data from visible and thermal channels of the AVHRR. Reference [75] studied the sea ice drift vectors which were automatically extracted from pairs of the AMSR-E images acquired in one or two day's interval by comparing with sea ice drift vectors manually extracted from pairs of cloudless MODIS im-

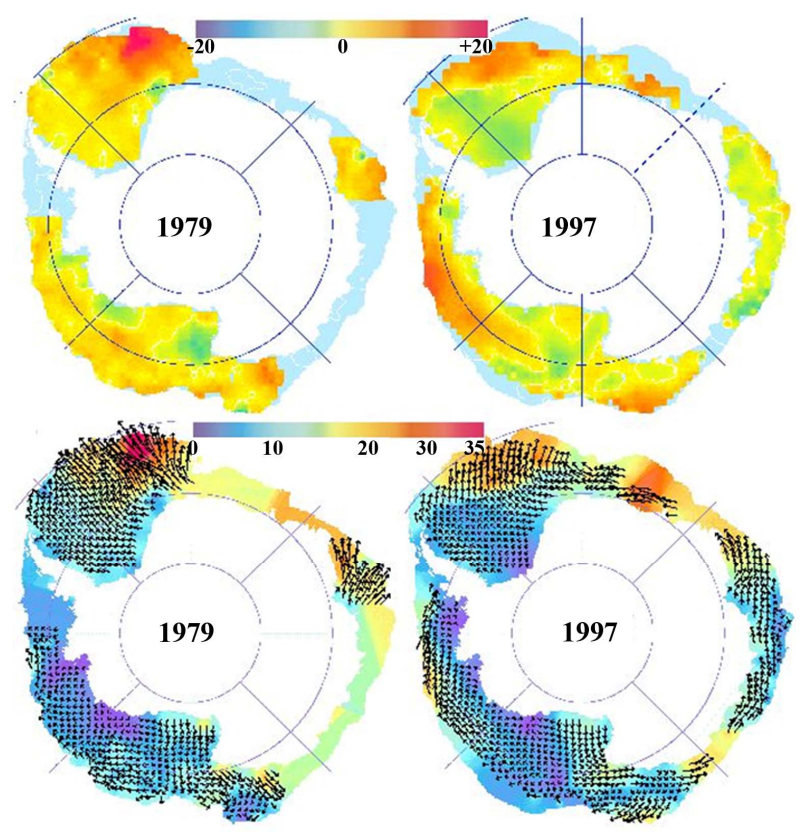

Figure 12. Sea ice drift anomaly (top) and sea ice drift velocity (bottom), in $\mathrm{cm} \cdot \mathrm{s}^{-1}$ [77]. 
ages acquired simultaneously with AMSR-E images. The cross correlation algorithm was used for automatically extracting sea-ice drift vectors from PMS images. Results have shown a good agreement with manual tracking from MODIS imagery.

With high quality SAR images sea ice drift can be automatically tracked. It has been suggested that combining different data sources (different sensors) can improve tracking reliability [76]. Further improvements of sea ice drift estimations can be expected by use of new sensors with better ground resolution and pixel size, and more optimized integration of various data.

Remote sensing technologies have evolved to remotely sense each aspect of sea ice. Often an informed combination of data sets from different sensors can improve accuracy and avoid ambiguity in derived results. Onset of melt season changes the physical structure and temperature of target sea ice area, thereby effectively changing its microwave signatures. If during that period surface features are used to derive the information, then dependence on microwave signatures will be reduced.

\section{Conclusions}

The vast areas of sea ice in the polar regions play a major role in polar climate processes and also influence the global climate significantly. In recent decades, starting with accurate satellite remote sensing of polar regions, sea ice extent has undergone drastic changes in Arctic and to some extent in the Antarctic. Arctic has lost its major portion of sea ice cover in 30 years whereas in Antarctic it has been slightly expanding during the same period. Sea ice is monitored by using different parameters for example, extent area, sea ice type, thickness, drift velocity, etc. Each parameter has its own significance and poses unique challenge to observe it. Historical or pre-satellite sea ice records provide long-term proxy data yet quality and reliability of such data restricts potential usage. Since the dawn of satellite remote sensing era, various sensors have been developed and deployed on satellite platforms (Table 2). First, visible and IR sensors were used to observe sea ice extent but proved to be inadequate due to cloudy conditions. Successively PMW sensors, active sensors like SAR, RA, LiDAR were developed to enhance resolution and coverage. India's MSMR on board IRS-P4/OCEANSAT-1 also contributed to the mapping and monitoring of polar sea ice. Using 18 $\mathrm{GHz}$ channel with horizontal polarization $0.5^{\circ} \times 0.5^{\circ}$ resolution sea ice maps were generated and its variation was studied from June 1999 to September 2001. We have compared and compiled different technologies to detect, observe and estimate sea ice features.

Current set of sensors have evolved from limited capabilities of earlier sensors in terms of spatial resolution and range of measurements. Sea ice extent and concentration are one of few parameters that have been studied, since reliable satellite observations began in 1979. Literature survey showed that PMS offer better monitoring capabilities than other sensors. Sea ice thickness is very important parameter which helps to monitor volume of sea ice. Primary sensors used to measure thickness provide high-resolution visible images for computing the albedo values and deriving thickness values by using conversion algorithms. Different ice types emit different radiation spectrally; it can be successfully exploited using PMS data. Surface roughness can be detected by using SAR signatures of target surface. When the sea ice is covered with snow, it can be monitored based on microwave signature of snow. A practical solution was suggested using scatterometer data which penetrates depth of snow to assess state and vertical extent of snow cover. Sea ice drift is also one of the important parameters to determine movement of ice pack and underlying current

Table 2. Different Sea Ice variables observed using satellite sensors and preferred datasets.

\begin{tabular}{|c|c|c|}
\hline Sea Ice Variable & Satellite Sensors & Preferred Data Sets \\
\hline Extent and Concentration & Visible/IR, Passive Microwave, and Scatterometer & $\begin{array}{l}\text { Daily global products MSMR, SSMI, AMSR-E, } \\
\text { MODIS and Scatterometer }\end{array}$ \\
\hline Thickness & $\begin{array}{l}\text { Visible/IR, Radar/Laser Altimeter, } \\
\text { and Passive Micrwave }\end{array}$ & $\begin{array}{l}\text { MODIS/other visible } \\
\text { imagery used for albedo measurements and GLAS/ICESat. }\end{array}$ \\
\hline Ice Type & $\begin{array}{c}\text { Scatterometer, } \\
\text { Active Microwave (SAR), and Passive } \\
\text { Microwave }\end{array}$ & $\begin{array}{l}\text { Passive Microwave Sensor data from MSMR, } \\
\text { SSMI. SAR data from ERS-1, } \\
\text { RISAT-1 }\end{array}$ \\
\hline Surface Roughness & Active Microwave (SAR), and Radar/Laser Altimeter & $\begin{array}{l}\text { SAR and Radar Altimetry data from CryoSat. } \\
\text { Laser Altimetry data from GLAS/ICESat. }\end{array}$ \\
\hline Snow Cover & Passive Microwave, and Scatterometer & Daily global products MSMR, SSMI, MSR-E \\
\hline Velocity/Drift & $\begin{array}{c}\text { Passive Microwave, } \\
\text { Scatterometer, and Active Microwave (SAR) }\end{array}$ & $\begin{array}{c}\mathrm{SSM} / \mathrm{I}, \mathrm{SAR} \\
\text { Scatterometer data }\end{array}$ \\
\hline
\end{tabular}


configuration. PMS data with automated algorithms are used to detect direction and speed of sea ice movement. Synthesis of existing research suggests various methods are available for sea-ice parameter extraction.

Through this review, a number of gaps were found in existing body of knowledge, a few topics are highlighted below which requires thorough investigation.

1) Accurate sea ice thickness estimation using LA, which has a tremendous potential for charting panAntarctic area, largely depends on accurate snowcover depth information. Lack of wide-area snow thickness information has stalled ice thickness measurements; snow depth based atlases are required to monitor year-on-year and seasonal variations.

2) As pointed out in the recent research works some Antarctic glaciers are experiencing unprecedented melting [78], which releases a vast amount of fresh water into coastal seas, and the impact of such processes on freezing-thawing cycle of sea ice is not well understood

3) High-speed katabatic winds constantly break and push large chucks of sea ice further from the continental margin, increasing the sea ice extent and impacting the drift course. Future studies should be directed to assess the impacts of such events. When such events open up polynas, the latent and sensible heat flux exchange with the atmosphere will affect the local air-sea heat budget.

4) ACC has significant role in Antarctic climatic processes, as oceans around Antarctica are warming [79]. Further studies should focus on the influence of ACC in cooling or warming of seas around Antarctica, and the impact on upwelling and mixing in and around polynas have not been explored in detail.

5) As SAM is enhanced and switched to positive mode [80], the westerlies shift poleward and girdle the continent; understanding how this change will affect sea ice formation and movement could shed light on hidden processes operating in the region.

The evolution of sensors has led to broad categorisation of sea ice parameters depending on physical features. A preferential datasets can be chosen to extract maximum possible information about parameters in question. Major remote-sensing satellite organisations all have planned improved satellite systems to be launched in near future. Few examples which would help monitoring sea ice parameters are as follows. For sea ice extent: VIIRS sensor onboard JPSS-1 is ideal. VIS/IR Imaging Radiometer sensor onboard Meteor-MP N1 and MERSI-2 onboard FY-3G will find many applications in cryospheric research when launched in 2014-15. Likewise, the planned launch of ATLAS aboard ICEsat-2 in 2014 will be very helpful in monitoring sea ice thickness. Other planned missions such as SRAL onboard Sentinel-3A, SAR-X onboard Meteor-M N3, WindRAD onboard FY-3E and SCAT onboard Meteor-M N3 will help detect different ice types. Effective remote sensing of polar sea ice is essential for understanding short-term and longterm effects of sea ice on regional climate in particular and global climate in general.

\section{Acknowledgements}

We thank NCAOR Director, Dr. S. Rajan, for the encouragement. This is NCAOR contribution 14/2013.

\section{REFERENCES}

[1] J. Turner, S. R. Colwell, G. J. Marshall, T. A. Lachlan-Cope, A. M. Carleton, P. D. Jones, V. Lagun, P. A. Reid and S. Iagovkina, "Antarctic Climate Change during the Last 50 Years," International Journal of Climatology, Vol. 25, No. 3, 2005, pp. 279-294. doi:10.1002/joc.1130

[2] R. G. Barry, "The Present Climate of the Arctic Ocean and Possible Past and Future States," In: Y. Herman, Ed., The Arctic Seas: Climatology, Oceanography, Geology and Biology, Van Nostrand Reinhold, New York, 1989, pp. 1-46.

[3] G. A. Maykut, "Energy Exchange over Young Sea Ice in the Central Arctic," Journal of Geophysical Research, Vol. 83, No. C7, 1978, pp. 3646-3658.

doi: 10.1029/JC083iC07p03646

[4] F. D. Carsey, "An Approach to Brine and Freshwater Fluxes Interpreted from Radar and Microwave Radiometer Data," In: P. C. Chu and J. S. Gascard, Eds., Deep Convection and Deep Water Formation in the Oceans, Elsevier Science Publishers, New York, 1991, pp. 123133. doi:10.1016/S0422-9894(08)70064-3

[5] K. Aagaard and E. Carmack, "The Role of Sea Ice and Other Fresh Water in the Arctic Circulation," Journal of Geophysical Research, Vol. 94, No. C10, 1989, pp. 14485-14498. doi:10.1029/JC094iC10p14485

[6] W. Smith and E. Sakshaug, "Polar Oceanography, Part B, Chemistry, Biology, and Geology," In: W. Smith, Ed., Polar Oceanography: Chemistry, Biology, and Geology, Academic Press, San Diego, 1990, pp. 477-517.

[7] R. Stouffer, S. Manabe and K. Bryan, "Interhemispheric Asymmetry in Climate Response to a Gradual Increase of Atmospheric $\mathrm{CO}_{2}$," Nature, Vol. 342, No. 6250, 1989, pp. 660-662. doi:10.1038/342660a0

[8] H. J. Zwally, D. Yi, R. Kwok and Y. Zhao, "ICESat Measurements of Sea Ice Freeboard and Estimates of Sea Ice Thickness in the Weddell Sea," Journal of Geophysical Research, Vol. 113, No. C2, 2008, p. 17 doi:10.1029/2007JC004284

[9] O.M. Johannessen, W. J. Campbell, R. Shuchman, S. Sandven, P. Gloersen, J. A. Johannessen, E. G. Josberger and P. M. Haugan, "13. Microwave Study Programs of Air-Ice-Ocean Interactive Processes in the Seasonal Ice Zone of the Greenland and Barents Seas," In: F. Carsey, Ed., Microwave Remote Sensing of Sea Ice, AGU Geo- 
physical Monograph 68, Washington DC, 1992, pp. 261289. doi:10.1029/GM068p0261

[10] O.M. Johannessen, M. Miles and E. Bjørgo, "The Arctic's Shrinking Sea Ice," Nature, Vol. 376, No. 126, 1995 , pp. 126-127. doi:10.1038/376126a0

[11] O. M. Johannessen, E. V. Shalina and M. W. Miles, "Satellite Evidence for an Arctic Sea Ice cover in transformation," Science, Vol. 286, No. 5446, 1999, pp. 1937-1939. doi:10.1126/science.286.5446.1937

[12] O. M. Johannessen, V. Yu Alexandrov, I. Ye Frolov, S. Sandven, L. H. Pettersson, L. P. Bobylev, K. Kloster, V. G. Smirnov, Y. U. Mironov and N. G. Babich, "Remote Sensing of Sea Ice in the Northern Sea Route: Studies and Applications," Praxis Publishing, UK, 2007, 472 p.

[13] C. R. Jackson and J. R. Apel, "Synthetic Aperture Radar. Marine User's Manual," National Oceanic and Atmospheric Administration, Washington DC, 2004.

[14] W. K. de la Mare, "Abrupt Mid-Twentieth-Century Decline in Antarctic Sea Ice Extent from Whaling Records," Nature, Vol. 389, 1997, pp. 57-60. doi:10.1038/37956

[15] S. Ackley, P. Wadhams, J. C. Comiso and A. P. Worby, "Decadal Decrease of Antarctic Sea Ice Extent Inferred from Whaling Records Revisited on the Basis of Historical and Modern Sea Ice Records," Polar Research, Vol. 22, No. 1, 2003, pp. 19-25. doi:10.1111/j.1751-8369.2003.tb00091.x

[16] C. Swithinbank, "Arctic Pack Ice from Below," Proceedings of an International Conference, Reykjavik, 10-13 May 1972, pp. 246-254.

[17] D. A. Rothrock, Y. Yu and G. A. Maykut, "Thinning of the Arctic Sea-Ice Cover," Geophysical Research Letters, Vol. 26, No. 23, 1999, pp. 3469-3472. doi:10.1029/1999GL010863

[18] P. Winsor, "Arctic Sea Ice Thickness Remained Constant during the 1990s," Geophysical Research Letters, Vol. 28, No. 6, 2001, pp. 1039-1041. doi:10.1029/2000GL012308

[19] A. P. Worby, I. Allison and V. Dirita, "Antarctic CRC Research Report: Cooperative Research Centre for the Antarctic and Southern Ocean Environment, Vol. 14-15," Antarctic CRC, Sandy Bay, 1999.

[20] P. Gloersen, W. J. Campbell, D. J. Cavalieri, J. C. Comiso, C. L. Parkinson and H. J. Zwally, "NASA SP-511: Arctic and Antarctic Sea Ice, 1978-1987: Satellite Passive-Microwave Observations and Analysis," NASA, Washington DC, 1992.

[21] D. K. Hall, J. R. Key, K. A. Casey, G. A. Riggs and D. J. Cavalieri, "Sea Ice Surface Temperature Product from MODIS," IEEE Transactions on Geosciences and Remote Sensing, Vol. 42, No. 5, 2004, pp. 1076-1087. doi:10.1109/TGRS.2004.825587

[22] D. J. Cavalieri, P. Gloersen, C. E. Parkinson, H. J. Zwally and J. C. Comiso, "Observed Hemispheric Asymmetry in Global Sea Ice Changes,” Science, Vol. 278, No. 5340, 1997, pp. 1104-1106.

[23] D. J. Cavalieri, C. L. Parkinson, N. DiGirolamo and A. Ivanoff, "Intersensor Calibration between F13 SSMI and F17 SSMI for Global Sea Ice Data Records," IEEE Geosciences and Remote Sensing Letters, Vol. 9, No. 2, 2012, pp. 233-236. doi:10.1109/LGRS.2011.2166754

[24] O. M. Johannessen, S. Sandven, K. Kloster, L. H. Pettersson, V. V. Melentyev, L. Bobylev and K. Y. Kondratyev, "ERS-1/2 SAR Monitoring of Dangerous Ice Phenomena along the Western Part of the Northern Sea Route," International Journal of Remote Sensing, Vol. 18, No. 12, 1997, pp. 2477-2481. doi: $10.1080 / 014311697217422$

[25] S. M. Bhandari, N. K. Vyas, M. K. Dash, A. Khanolkar, N. Sharma, N. Khare and P. C. Pandey, "Simultaneous MSMR and SSM/I Observations and Analysis of Sea Ice Characteristics over the Antarctic Region," International Journal of Remote Sensing, Vol. 26, No. 15, 2005, pp. 3123-3136. doi:10.1080/01431160500104376

[26] K. C. Sahu, "Textbook of Remote Sensing and Geographical Information Systems," Atlantic Publishers, New Delhi, 2007, pp. 153-160.

[27] H. J. Zwally, J. C. Comiso, C. L. Parkinson, W. J. Campbell, F. D. Carsey and P. Gloersen, "NASA SP-459: Antarctic Sea Ice, 1973-1976: Satellite Passive-Microwave Observations," NASA, Washington DC, 1983.

[28] C. L. Parkinson, J. C. Comiso, H. J. Zwally, D. J. Cavalieri, P. Gloersen and W. J. Campbell, "NASA SP-489: Arctic Sea Ice, 1973-1976: Satellite Passive-Microwave Observations," NASA, Washington DC, 1987.

[29] H. J. Zwally, J. C. Comiso, C. L. Parkinson, D. J. Cavalieri and P. Gloersen, "Variability of Antarctic Sea Ice 1979-1998," Journal of Geophysical Research, Vol. 107, No. C5, 2002, pp. 9-1-9-19.

[30] H. B. Gordon and S. P. O'Farrell, “Transient Climate Change in the CSIRO Coupled Model with Dynamic Sea Ice," Monthly Weather Review, Vol. 125, No. 5, 1997, pp. 875-907.

doi: 10.1175/1520-0493(1997)125<0875:TCCITC $>2.0 . C$ $\mathrm{O} ; 2$

[31] S. Manabe, M. J. Spelman and R. J. Stouffer, "Transient Responses of a Coupled Ocean-Atmosphere Model to Gradual Changes of Atmospheric $\mathrm{CO}_{2}$, Part II, Seasonal Response," Journal of Climate, Vol. 5, No. 2, 1992, pp. 105-126.

doi:10.1175/1520-0442(1992)005<0105:TROACO $>2.0 . \mathrm{C}$ $\underline{\mathrm{O} ; 2}$

[32] N. K. Vyas, M. K. Dash, S. M. Bhandari, N. Khare, A. Mitra and P. C. Pandey, "Large Scale Antarctic Features Captured by Multi-Frequency Scanning Microwave Radiometer On-Board OCEANSAT-1," Current Science, Vol. 80, No. 10, 2001, pp. 1319-1322.

[33] N. Khare, N. Sharma, S. M. Bhandari and N. K. Vyas "Utility of OCEANSAT-1 OCM Data in Deciphering Antarctic Features," Current Science, Vol. 93, No. 3, 2007, pp. 292-294.

[34] F. Nishio and J. C. Comiso, "The Polar Sea Ice Cover from Aqua/AMSR-E," Proceedings of the 25th International Geosciences and Remote Sensing Symposium (IGARSS'05), Melbourne, 25-29 July 2005, pp. 49334937.

[35] L. Ning, F. Xie, W. Gu, Y. Xu, S. Huang, S. Yuan, W. Cui and J. Levy, "Using Remote Sensing to Estimate Sea 
Ice Thickness in the Bohai Sea, China Based on Ice Type," International Journal of Remote Sensing, Vol. 30, No. 17, 2009, pp. 4539-4552,

[36] H. Su and Y. Wang, "Using MODIS Data to Estimate Sea Ice Thickness in the Bohai Sea (China) in the 2009-2010 Winter," Journal Geophysical Research, Vol. 117, No. C10, 2012, Article ID: C10018. doi:10.1029/2012JC008251.

[37] X. Wang, J. Key and Y. Liu, "A Thermodynamic Model for Estimating Sea and Lake Ice Thickness with Optical Satellite Data," Journal Geophysical Research, Vol. 115, No. C12, 2010, Article ID: C12035. doi:10.1029/2009JC005857.

[38] S. Liang, "Narrowband to Broadband Conversions of Land Surface Albedo: I. Algorithms," Remote Sensing of Environment, Vol. 76, No. 2, 2001, pp. 213-238. doi:10.1016/S0034-4257(00)00205-4.

[39] S. Liang, "A Direct Algorithm for Estimating Land Surface Broadband Albedos from MODIS Imagery," IEEE Transactions on Geosciences and Remote Sensing, Vol. 41, No. 1, 2003, pp. 136-145.

[40] Y. Yu and D. A. Rothrock, "Thin Ice Thickness from Satellite Thermal Imagery," Journal Geophysical Research, Vol. 101, No. C11, 1996, pp. 25753-25766.

[41] L. Kaleschke, X. Tian-Kunze, N. Maßß, M. Mäkynen and M. Drusch, "Sea Ice Thickness Retrieval from SMOS Brightness Temperatures during the Arctic Freeze-Up Period," Geophysical Research Letters, Vol. 39, No. 5, 2012, pp. 1-5. doi:10.1029/2012GL050916.

[42] M. Makynen, B. Cheng and M. Simila, "On the Accuracy of Thin-Ice Thickness Retrieval Using MODIS Thermal Imagery over Arctic First-Year Ice," Annals of Glaciology, Vol. 54, No. 62, 2013, pp. 87-96. doi:10.3189/2013AoG62A166.

[43] N. T. Kurtz and T. Markus, "Satellite Observations of Antarctic Sea Ice Thickness and Volume," Journal Geophysical Research, Vol. 117, No. C08, 2012, Article ID: C08025. doi:10.1029/2012JC008141.

[44] A. Mitra, I. M. L. Das, M. K. Dash, S. M. Bhandari and N. K. Vyas, "Impact of Ice-Albedo Feedback on Hemispheric Scale Sea-Ice Melting Rates in the Antarctic," Current Science, Vol. 94, No. 8, 2001, p. 1044.

[45] M. Shokr, A. Lambe and T. Agnew, "A New Algorithm (ECICE) to Estimate Ice Concentration From Remote Sensing Observations: An Application to 85-GHz Passive Microwave Data," IEEE Transactions on Geosciences and Remote Sensing, Vol. 46, No. 12, 2008, pp. 41044121. doi:10.1109/TGRS.2008.2000624

[46] S. G. Beaven and S. P. Gogineni, "Fusion of Satellite SAR with Passive Microwave Data for Sea Ice Remote Sensing," In: C. Tsatsoulis and R. Kwok, Eds., Analysis of SAR Data of the Polar Oceans: Recent Advances, Springer, Berlin, 1998, pp. 91-109. doi:10.1007/978-3-642-60282-5 5

[47] M. Lythe, A. Hauser and G. Wendler, "Classification of Sea Ice Types in the Ross Sea, Antarctica from SAR and AVHRR Imagery," International Journal of Remote Sensing, Vol. 20, No. 15-16, 1999, pp. 3073-3085. doi:10.1080/014311699211624

[48] N. Y. Zakhvatkina, V. Y. Alexandrov, O. M. Johannessen, S. Sandven and I. Y. Frolov, "Classification of Sea Ice Types in ENVISAT Synthetic Aperture Radar Images," IEEE Transactions on Geoscience and Remote Sensing, Vol. 51, No. 5, 2013, pp. 2587-2600. doi:10.1109/TGRS.2012.2212445.

[49] W. Dierking and T. Busche, "Sea Ice Monitoring by L-Band SAR: An Assessment Based on Literature and Comparisons of JERS-1 and ERS-1 Imagery," IEEE Transactions on Geoscience and Remote Sensing, Vol. 44, No.2, 2006, pp. 957-970, doi:10.1109/TGRS.2005.861745

[50] A. W. Nolin, F. M. Fetterer and T. A. Scambos, "Surface Roughness Characterizations of Sea Ice and Ice Sheets: Case Studies with MISR Data," IEEE Transactions on Geoscience and Remote Sensing, Vol. 40, No. 7, 2002, pp. 1605-1615. doi:10.1109/TGRS.2002.801581

[51] H. Bi, X. F. Yang, Z. W. Li and X. Zhou, "Sea Ice SmallScale Surface Roughness Estimation Based on AMSR-E Observations," International Journal of Remote Sensing, Vol. 34, No. 12, 2013, pp. 4425-4448.

[52] N. T. Kurtz, T. Markus, D. J. Cavalieri, W. Krabill, J. G. Sonntag and J. Miller, "Comparison of ICESat Data with Airborne Laser Altimeter Measurements over Arctic Sea Ice," IEEE Transactions on Geoscience and Remote Sensing, Vol. 46, No. 7, 2008, pp. 1913-1924. doi:10.1109/TGRS.2002.801581

[53] K. F. Kunzi, S. Patil and H. Rott, "Snow-Cover Parameters Retrieved from Nimbus-7 Scanning Multichannel Microwave Radiometer (SMMR) Data," IEEE Transactions on Geoscience and Remote Sensing, Vol. 20, No. 4, 1982, pp. 452-467. doi:10.1109/TGRS.1982.350411

[54] H. Rott, K. Kunzi and S. Patil, "Temporal and Spatial Variations of Snow Properties Derived from Nimbus-7 SMMR Data," Proceedings of 20th URSI General Assembly, Symposium of Remote Sensing, Washington DC, 10-19 August 1981.

[55] A. T. C. Chang, J. L. Foster, D. K. Hall, A. Rango and B. K. Hartline, "Snow Water Equivalent Estimation by Microwave Radiometry," Cold Regions Science and Technology, Vol. 5, No. 3, 1982, pp. 259-267. doi:10.1016/0165-232X(82)90019-2

[56] B. Goodison, "Determination of Areal Snow Water Equivalent on the Canadian Prairies Using Passive Microwave Satellite Data," Proceedings of the IGARSS'89 Symposium, Vancouver, 10-14 July 1989, pp. 1243-1246.

[57] B. E. Goodison and A. E. Walker, "Canadian Development and Use of Snow Cover Information from Passive Microwave Satellite Data," In: B. Choudhury, et al., Eds., Passive Microwave Remote Sensing of Land-Atmosphere Interactions, VSP Press, 1995, pp. 245-262.

[58] C. Mätzler, "Microwave Sensors for Measuring Avalanche-Critical Snow Parameters," In: B. Salm and H. Gubler, Eds., International Symposium on Avalanche Formation, Movement and Effects, IAHS Publication, Davos, 1987, pp. 149-160.

[59] A. E. Walker and A. Silis, "Snow-Cover Variations over 
the MacKenzie River Basin, Canada, Derived from SSM/I Passive Microwave Satellite Data," Annals of Glaciology, Vol. 34, No. 1, 2002, pp. 8-14. doi:10.3189/172756402781817680

[60] R. Bindschadler, H. Choi, C. Shuman and T. Markus, "Detecting and Measuring New Snow Accumulation on Ice Sheets by Satellite Remote Sensing," Remote Sensing of Environment, Vol. 98, No. 4, 2005, pp. 388-402. doi:10.1016/j.rse.2005.07.014

[61] A. T. C. Chang and L. S. Chiu, "Global Snow Variation Derived from SMMR: Preliminary Results," In: S. F. Ackley and W. F. Weeks, Eds., Sea Ice Properties and Processes, CRREL Monogram, U.S. Army Corps of Eng., Hanover, 1990, pp. 213-217.

[62] T. Markus and D. J. Cavalieri, "Snow Depth Distribution over Sea Ice in the Southern Ocean from Satellite Passive Microwave Data," In: M. O. Jeffries, Ed., Antarctic Sea Ice Physical Processes, Interactions and Variability, Antarctic Research Series, Vol. 74, AGU, Washington DC, 1998, pp. 19-40. doi:10.1029/AR074p0019

[63] V. Renganathan, "Arctic Sea Ice Freeboard Heights from Satellite Altimetry," Ph.D. Thesis, University of Calgary, Calgary, 2010.

[64] J. C. Comiso, D. J. Cavalieri and T. Markus, "Sea Ice Concentration, Ice Temperature, and Snow Depth Using AMSR-E Data," IEEE Transactions on Geoscience and Remote Sensing, Vol. 41, No. 2, 2003, pp. 243-252. doi:10.1109/TGRS.2002.808317

[65] R. E. J. Kelly and A. T. C Chang, "Development of a Passive Microwave Global Snow Depth Retrieval Algorithm for SSM/I and AMSR-E Data," Radio Science, Vol. 38, No. 4, 2003, p. 8076. doi:10.1029/2002RS002648

[66] N. T. Kurtz, T. Markus, D. J. Cavalieri, L. C. Sparling, W. B. Krabill, A. J. Gasiewski and J. G. Sonntag, "Estimation of Sea Ice Thickness Distributions through the Combination of Snow Depth and Satellite Laser Altimetry Data," Journal Geophysical Research, Vol. 114, No. C10, 2009, pp. 1-16. doi:10.1029/2009JC005292

[67] S. V. Nghiem, K. Steffen, R. Kwok and W. Y. Tsai, "Detection of Snowmelt Regions on the Greenland Ice Sheet Using Diurnal Backscatter Change," Journal of Glaciology, Vol. 47, No. 159, 2001, pp. 539-547. doi: $10.3189 / 172756501781831738$

[68] J. Foster, D. Hall and J. Eylander, “A New Blended Snow Product Using Visible, Microwave and Scatterometer Satellite Data," Proceeding of IEEE International Geocience and Remote Sensing Symposium (IGARSS 2009), Cape Town, 12-17 July 2009, pp. II-559-II-562.

[69] R. Kwok, A. Schweiger, D. A. Rothrock, S. Pang and C. Kottmeier, "Sea Ice Motion from Satellite Passive Microwave Imagery Assessed with ERS SAR and Buoy Motions," Journal Geophysical Research, Vol. 103, No. C4, 1998, pp. 8191-8214. doi:10.1029/97JC03334
[70] A. K. Liu and D. J. Cavalieri, "On Sea Ice Drift from the Wavelet Analysis of the Defense Meteorological Satellite Program (DMSP) Special Sensor Microwave Imager (SSM/I) Data," International Journal of Remote Sensing, Vol. 19, No. 7, 1998, pp. 1415-1423. doi:10.1080/014311698215522

[71] A. K. Liu and Y. Zhao, "Sea Ice Motion from Wavelet analysis of Satellite Data," Proceedings of the Eighth International Offshore and Polar Engineering Conference, Vol. 3, Montréal, May 24-29 1998, pp. 30-35.

[72] M. R. Drinkwater, "Active Microwave Remote Sensing Observations of Weddell Sea Ice," In: M. O. Jeffries, Ed., Antarctic Sea Ice: Physical Processes, Interactions and Variability, Antarctic Research Series, Vol. 74, AGU, Washington DC, 1998, pp. 187-212. doi:10.1029/AR074p0187

[73] J. Maslanik, T. Agnew, M. Drinkwater, W. Emery, C. Fowler, R. Kwok and A. Liu, "Summary of Ice-Motion Mapping Using Passive Microwave Data," NSIDC Special report-8, National Snow and Ice Data Centre, CIRES, Boulder, 1998.

[74] S. Schwegmann, C. Haas, C. Fowler and R. Gerdes, "A Comparison of Satellite-Derived Sea Ice Motion with Drifting Buoy Data in the Weddell Sea, Antarctica," Annals of Glaciology, Vol. 52, No. 57, 2010, pp. 103-110. doi:10.3189/172756411795931813

[75] R. Yaguchi and K. Cho, "Validation of Sea Ice Drift Vector Extraction from AMSR-E and SSM/I Data by Using MODIS Data," Journal of The Remote Sensing Society of Japan, Vol. 29, No. 1, 2009, pp. 242-252.

[76] F. Girard-Ardhuin and R. Ezraty, "Enhanced Arctic Sea Ice Drift Estimation Merging Radiometer and Scatterometer Data," IEEE Transactions on Geoscience and Remote Sensing, Vol. 50, No. 7, 2012, pp. 2639-2648. doi:10.1109/TGRS.2012.2184124

[77] C. Schmitt, C. Kottmeier, S. Wassermann and M. Drinkwater, "Atlas of Antarctic Sea Ice Drift," Institut für Meteorologie und Klimaforschung, Universität Karlsruhe 2004.

[78] B. J. Davies, J. L. Carrivick, N. F. Glasser, M. J. Hambrey and J. L. Smellie, "Variable Glacier Response to Atmospheric Warming, Northern Antarctic Peninsula, 1988-2009," The Cryosphere, Vol. 6, No. 5, 2012, pp. 1031-1048. doi:10.5194/tc-6-1031-2012

[79] S. Gille, "Decadal-Scale Temperature Trends in the Southern Hemisphere Ocean," Journal of Climate, Vol. 21, No. 18, 2002, pp. 4749-4765. doi:10.1175/2008JCLI2131.1

[80] D. W. J. Thompson and S. Solomon, "Interpretation of Recent Southern Hemisphere Climate Change," Science, Vol. 296, No. 5569, 2002, pp. 895-899. 


\section{List of Acronyms}

\begin{tabular}{|c|c|}
\hline AARI & Arctic and Antarctic Research Institute \\
\hline ACC & Antarctic Circumpolar Current \\
\hline ADEOS & Advanced Earth Observing Satellite \\
\hline AMSR-E & Advanced Microwave Scanning Radiometer-EOS \\
\hline $\mathrm{AO}$ & Arctic Oscillations \\
\hline ASAR & advanced SAR \\
\hline ASI & ARTIST sea ice \\
\hline ATLAS & Advanced Topographic Laser Altimeter System \\
\hline AVHRR & Advanced Very-High Resolution Radiometer \\
\hline $\mathrm{BA}$ & Bellingshausen-Amundsen \\
\hline $\mathrm{CCD}$ & Charged Coupled Devices \\
\hline CIS & Canadian Ice Service \\
\hline DMSP & Defence Meteorological Satellite Program \\
\hline ECICE & Environment Canada's Ice Concentration Extractor \\
\hline ERS & European Remote Sensing \\
\hline ESA & European Space Agency \\
\hline ESAR & Experimental synthetic aperture radar \\
\hline ESMR & Electrically Scanning Microwave Radiometer \\
\hline FY-3E & Feng-Yun 3E \\
\hline FY-3G & Feng-Yun 3G \\
\hline FYI & First Year Ice \\
\hline GLAS & Geoscience Laser Altimeter System \\
\hline IRS & Indian Remote Sensing Satellites \\
\hline ISRO & Indian Space Research Organisation \\
\hline JPSS & Joint Polar Satellite System \\
\hline LiDAR & Light Detection and Ranging \\
\hline LISS & Linear Imaging Self Scanner \\
\hline MERSI & Medium Resolution Spectral Imager \\
\hline MIRAS & Microwave Imaging Radiometer using Aperture Synthesis \\
\hline MISR & Multi-angle Imaging Spectro-Radiometer \\
\hline MODIS & Moderate Resolution Imaging Spectrometer \\
\hline MSMR & Multi-frequency Scanning Microwave Radiometer \\
\hline MSS & Multispectral scanner \\
\hline
\end{tabular}




\section{Continued}

\begin{tabular}{|c|c|}
\hline MYI & Multi-Year Ice \\
\hline NAO & North Atlantic Oscillations \\
\hline NASA's & National Aeronautical and Space Administration \\
\hline NIC & National Ice Centre \\
\hline NIR & Near Infrared \\
\hline $\mathrm{NN}$ & Neural Network \\
\hline NOAA & National Oceanic and Atmospheric Administration \\
\hline NESDIS & National Environmental Satellite, Data, and Information Service \\
\hline NSCAT & NASA's Scatterometer \\
\hline NSIDC & National Snow and Ice Data Centre \\
\hline OCM & Ocean Colour Monitor \\
\hline $\mathrm{ON}$ & open water/nilas \\
\hline PAN & panchromatic \\
\hline PCT & polarization corrected temperature \\
\hline PMW & Passive Microwave \\
\hline RA & Radar Altimeter \\
\hline RBV & return-beam vidicon \\
\hline SAM & Southern Annular Mode \\
\hline SAR & Synthetic aperture radars \\
\hline SAT & surface air temperatures \\
\hline SD & standard deviations \\
\hline SIC & sea-ice concentration \\
\hline SLAR & side-looking real aperture radar \\
\hline SMMR & Scanning Multichannel Microwave Radiometer \\
\hline SMOS & Soil Moisture and Ocean Salinity \\
\hline SRAL & Satnav receiver and laser \\
\hline $\mathrm{SSM} / \mathrm{I}$ & Special Sensor Microwave/Imager \\
\hline SSMIS & Special Sensor Microwave Imager/Sounder \\
\hline SST & sea surface temperature \\
\hline SWIR & shortwave Infrared \\
\hline TIROS & Television Infrared Observation Satellite \\
\hline TM & Thematic Mapper \\
\hline ULS & Upward looking sonar \\
\hline USAFGWC & United States Air Force Global Weather Center \\
\hline
\end{tabular}




\section{Continued}

\begin{tabular}{ll}
\hline USCGC & United States Coast Guard Cutter \\
USGS & United States Geological Survey \\
USSR & Union of Soviet Socialist Republic \\
VIIRS & Visible Infrared Imaging Radiometer Suite \\
WiFS & Wide Field Sensor \\
WindRAD & Wind Radar \\
WSM & Wide Swath Mode \\
WV & Water Vapour \\
WWII & World War II
\end{tabular}

